\title{
Simultaneous Learning of Two Foreign Languages, English and French, by Adult Persian-Speaking Learners
}

\author{
Rouhollah Rahmatian $^{1} \&$ Mahdieh Farshadjou ${ }^{1}$ \\ ${ }^{1}$ French Education Department, Faculty of Humanities, Tarbiat Modares University, Tehran, Iran \\ Correspondence: Rouhollah Rahmatian, Associate Professor, French Education Department, Faculty of \\ Humanities, Tarbiat Modares University, P. O. Box 14115-111, Tehran, Iran. Tel: 98-218-288-4648. E-mail: \\ r_rahmatian@yahoo.com/rahmatir@modares.ac.ir
}

Received: July 1, 2013 Accepted: September 18, 2013 Online Published: September 26, 2013

doi:10.5539/ies.v6n10p70

URL: http://dx.doi.org/10.5539/ies.v6n10p70

\begin{abstract}
In today's world, a good command of more than two foreign languages is a commonplace necessity. However, this is not the case for the majority of language learners in Iran. The foreign languages which could be of any avail to them are neither close to Persian nor have any daily social usage. The present research aims at promoting this linguistic ability by improving the methods of simultaneous teaching of two foreign languages in Iran. Through studying the concept of bilingualism and acquiring a more profound insight into simultaneous teaching, a plan was designed for teaching 20 sessions of English and French to two groups: Group A comprised of beginner learners in both languages and Group B of intermediate learners in English who were beginners in French. Thirty-six participants took part in the project. Twelve were in the simultaneous classes and 24 in the Control Groups, assigned into four groups of six based on language proficiency levels. The following results were reached based on the average grades of the final exam and the placement tests (given both before and after the course). On the whole, Groups A and B obtained higher averages than the Control Groups. The findings of this study suggest that not only simultaneous learning is not an impeding factor but also it reinforces learning of the two languages. We hope that this research will be a first step towards a more extensive study on a national scale for Iranians and especially for children to be multilingual.
\end{abstract}

Keywords: bilingualism, English as a Foreign Language, French as a Foreign Language, simultaneous learning

\section{Introduction}

\subsection{Introduction to the Problem}

A general movement towards multilingualism has recently started throughout the whole world. The concept is not new in itself. What we are looking for, however, is simultaneous learning of two foreign languages for adults. In Europe, some remarkable projects, such as EuRom4 or Galatea, have been conceptualized for teaching simultaneous reading of several languages, all of which originated from Roman languages. Such projects have never been realized in Iran or other Asian countries.

Alongside English, Arabic has been taught in parallel in Iran schools for years. Students receiving their high school diploma, however, do not generally master either. Arabic is alphabetically and lexically near Persian, Iranian learners' mother tongue, but the foreign languages like English, French, German, Spanish, which they wish to learn, are distant from Persian both in alphabet and structure. Therefore, the advantage of a shared root in European projects would be missing in our case. Although this is not a linguistic study, the need that these adults feel to follow extra courses in language institutes has encouraged us to find a way to make their learning more time-saving and fruitful, letting Iranians become acceptable polyglots in the near future. We believe that Iranian learners' language learning capacities are high. By applying new efficient methods and approaches, simultaneous learning, though appearing to be implausible, can be developed successfully if scientifically planned.

To organize our study project, first we reviewed main language learning process features: neuro-linguistics and sociolinguistics studies, particularly in bi/multilingualism, as the closest notion to simultaneous learning and teaching, since simultaneous learning of more than one language is basically dealt with in such studies. Then, based on these, our project was designed mainly inspired by two recent articles by Germain \& Netten (2011 \& 
2012), both dealing with EFL and FLE contributing researches into language skills development in language classes.

\subsection{Qualitative vs. Quantitative}

This research may be considered either as quantitative or qualitative by some, or perhaps neither by some other. We could not support, neither financially nor technically, a large number of participants, at least thirty according to quantitative study rules and ninety taking into account the control groups. Given large numbers, the quality of the course would be highly degraded; collaboration of more professional teachers and observers would have been required; the issues of place, time, study materials and the requisite expenses were all of concern, as well. Following qualitative rules, we could not work on more than 10 people; this, implying that in each class there must be no more than two students, again would not lead to satisfactory results since tutoring and public classes' needs, outcomes and methods are far diverse. Thus, as we were eager to realize the project, we resolved to carry out the program for classes of ten students, similar to normal classes in Iran. Accordingly, our study has the two aspects, qualitative and quantitative in parallel.

\section{$1.3 \mathrm{Bi} /$ Multilingualism and Intelligence, Age, Fluency \& Code Shifting}

Classification and definition of bilingualism vary between researches from mastery in both languages to the lowest understanding of either of the two languages. Balanced bilingualism is usuallyrare and many bilinguals are more competent in one language, called the dominant language. This dominance can have various reasons the most important of which are: culture, religion, economics, technology and education (Li Wei, 2000). These are both motivations for learning another language and mastering it through frequent use. The accepted definition in this article however is a level of linguistic knowledge which enables the speaker to communicate in both languages. In this definition, mistakes and errors, in structure, vocabulary or pronunciation not constituting an obstacle to communication, are considered as acceptable. Thus, fundamental concepts in bilingualism can stand as a solid base for designing the project of simultaneous teaching and learning of two languages.

If language is considered as the outcome of a general learning process, the individuals with moderate intellectual capacity should likewise face difficulties with language. This is not necessarily the case. There are on the other hand reports of extremely brilliant people who have language troubles (Mehler, Pallier, \& Christophe, 1996). Therefore, learning a language, as many studies have shown, is not essentially directlty related to that of intelligence and "given adequate environmental input, children normally acquire highly proficient spoken language without conscious effort or formal tuition" (Fisher \& Scharff, 2009, p. 166). Language learning of an adult is nonetheless different from a child from a neurological point of view. It is now known that a second language belatedly and not perfectly learned retains a different cortical representation which adequately differs from that of the mother tongue (Mehler et al., 1996). Some bilinguals have shown more extensive activity along the left prefrontal cortex, which could be due to the level of L2 proficiency rather than to the age of acquisition (Muñoz \& Singleton, 2011). An exception, however, is the study by Wartenburger et al. (2003) that examines late native-like bilinguals. Their study reports that these highly proficient bilinguals activate the prefrontal cortex more broadly. This can suggest that grammatical processing may be neurologically wired in. In regard to this grammatical processing, Abutalebi (2008), in his review of neuroimaging studies focusing also on lexico-semantic processing in bilinguals, records three styles of studies: "those that use an artificial grammar, those concerned with L1 processing (in particular with syntactic encoding for the characterization of the neural structures mediating grammar), and those focusing on grammatical processing in L1 and L2 in bilinguals" (2008: 466-478).

Overall, it can be concluded that findings of certain neuro-linguistic studies conducted in the 1990s (e.g. Weber-Fox \& Neville, 1996; Kim et al., 1997) cannot offer conclusive confirmation regarding a critical language learning period. This can be mainly because relating modifications in brain activation patterns to alterations in L2 proficiency have been unsuccessful. Some recent studies have also revised the same issue, taking into consideration the apparent onset age, L2 proficiency and language use. Such studies which could fulfill this condition are too few to deduce worthy conclusions and extract applicable implications (Muñoz \& Singleton, 2011). Therefore, it has been suggested that one can never perfectly master a second language which has been belatedly learned/acquired (age 10 or later), particularly with regards to pronunciation (Mehler et al., 1996). To put it differently, at least in non-instructional settings, early acquirers tend to end up indistinguishable from native speakers, whereas later acquirers do not (Muñoz \& Singleton, 2011). If achieving mastery equal to natives is the main question here, Pavlenko \& Lantolf (2000) advocate that, above anything else, late bilingualism gets initiated intentionally, that is people want to do it and this motivates them to reach a good level of proficiency. This might sometimes make it difficult to distinguish them from natives which they surprisingly try to avoid. In 
this regard, Kinsella (2009) has reported that some of the native English speakers in her study lost their enthusiasm to become native-like in French, residing for a short time in France, and realized they could appreciate the advantages of being a foreigner.

There is again this well-documented belief that bilinguals generally manage a smaller vocabulary repertoire in each language than monolinguals do (Perani et al., 2003; Portocarrero, Burright, \& Donovick, 2007). Their deficit in lexical access and retrieval perseveres with aging (Gollan et al., 2007). Although another study by Gollan et al. (2008) indicated that word frequency is directly related to the aging process, in that older bilinguals confirmed a smaller deficit for low-frequency words. We know that bilingual language production requires perpetual involvement of the executive control system to manage attention to the target language, and then it is possible that this experience enhances that system, making it more robust for other functions. Thus, in contrast to the negative effects of bilingualism found for vocabulary size and rapid lexical retrieval, bilingualism should have an advantageous effect on the function of executive control (Bialystok, 2008). The primary processes in the executive system are inhibition, shifting of mental sets (task switching or cognitive flexibility), and updating information in working memory (Miyake et al., 2000).

In fluent bilinguals who frequently speak two languages, both languages are active and available even when the other is being used (Kroll, Bobb, \& Wodniecka, 2006; Kaushanskaya, \& Marian, 2007). Such a condition creates the question of attention control, which distinctively concerns bilinguals -the needs to appropriately pick a form that meets all the criteria for form and meaning; this is, however, part of the target language and not the competing system.

The need to control attention to the target system in the context of an activated and competing system is the single feature that makes bilingual speech production most different from that of monolinguals and is at the same time responsible for both the cognitive and linguistic consequences of bilingualism. [...] Across a wide range of studies investigating a variety of abilities, it is clear that bilingualism is an experience that has significant consequence for cognitive performance. (Bialystok, 2008, p. 3)

Besides, based on a study done by Bregy, Brohy \& Fuchs (2000), it can be affirmed that bilingualism has no negative effects on the first language of the learner. That is learners achieve positive results in L2, which is comparable to monolingual learners.

However, there are certainly several forms of linguistic transference. We know that these phenomena are not necessarily limited to L1. That is, L2 can also intervene between L2 and L3, where the perception of a greater similarity is established between L1 and L3, which, according to Trévisiol (2006), means a certain level of L2 proficiency has been already reached. Odlin (2005) believes "whether or not learners can fully succeed in overcoming the influence of L1 (or perhaps L2 in the case of L3 acquisition)", they can successfully use the foreign language. Moreover, such ability, may affect their mother tongue and "the use of their native language and perhaps [they] restructure somewhat their cognitive capacities" (Odlin, 2005, p. 17).

Borrowing words from already acquired languages happens at intermediate level when communicative pressure is too high in comparison to the knowledge, probably insufficiently appropriated: beginners therefore rely on L1 for functional words and on L2 for lexical words, while intermediate learners rather call their L2 for borrowing functional words (Trévisiol, 2006).

Muñoz (2006) in his study affirms that the translinguistic influence (loanwords and changes in code) is more frequent among incompetent students (Möhle, 1989; Ringbom, 1987; Poulisse, 1990; Navés et al., 2005). Similar results have also been reported that students with a higher skill level rely more on lexical transfers and code shifts, which is not to be noticed among high level students (Muñoz, 2006: 12). Such cases can be regarded as what Kellerman (1991) calls compensation strategies. The term is defined by Oxford as "overcoming limitations in speaking and writing" (1990, p. 17). Put the other way round, even when a learner recognizes a word, motivation may be too low to inspire him or her to use the correct form. However, not all results are consistent, since effective factors in transference are numerous. Such seemingly contradictory results obtained in research studies on the role of competence in linguistic influence may be partly the result of language mode (oral vs. written) as oral beginner language learners include more unintentional code switching than more advanced learners. (Poulisse \& Bongaerts, 1994)

Through all these, we come to the conclusion that regarding age it is never late to start learning a new language and certain level of proficiency can be still achieved. Besides, there are some who wish not to be really native-like; if for some an acceptable bilingual is the one who masters two languages like a native for many the ability of communication is the criterion to be both appreciated and approved of. Question of transference and vocabulary size, however still discussed, has lost its importance and nowadays prominence is given to 
communication abilities which are not greatly affected by foreign accent, mispronunciation or even sometimes improper word order or structure. This is not to say that we support incorrect language use but that it should not prevent us from learning more than one foreign language, insofar as mistakes do not disturb communication or appropriateness of language.

\section{Methodology}

Linguistic, neuro-linguistic, sociologic and sociolinguistic studies on people who learn and speak more than one language have been the focal point of this research, based on which we found out that so many factors can intervene in the formation of a multilingual person, and practically no research can definitely admit a fixed fact. Linguistic interference is however likely to occur more when the circumstances of learning two languages are very similar, especially in the current project, where the two languages, English and French, share a similar graphical and auditory close form, both quite far from learners' maternal language, Persian. Physical and non-physical characteristics of people, the dominance of memory in each individual (auditory, visual ...), personal and social interest, etc. are all important in successful learning, but this ideal course where all these personal, social, economic, etc. parameters are satisfied, seems to never meet the prerequisites to be realized.

\subsection{Research Design}

In this research, public language classes in institutes of Tehran, Iran were simulated, with the mere difference being simultaneous bilingual courses and also the presence of an observer who, to observe all courses, through chatting with learners, created friendships and could reduce any plausible negative effects to a minimum. To reduce interference effects as much as possible, under our limited budget, time and facilities, we tried to provide some central circumstances. Since the visual sense plays an important role in learning, many of these conditions involved visual memory such as classroom (spatial forms, different classes for each language), markers of different colors or even teacher's gender.

\subsection{Participants Characteristic, Sample Size}

The notification of the project was shared in libraries and universities. Interested people could register online. Two days were assigned for interviews to determine their English level. Among applicants, twelve were admitted and classified for simultaneous learning, regarding language level and age (20-29 year old). For single-language classes, the normal procedure of language institutes' placement test was followed with the same age group being considered. A total of thirty-six women and men participated in this project. Twelve learners followed simultaneous courses in two groups of six, grouped according to their level of English proficiency, into beginner (A) and intermediate (B). Twenty-four learners divided into four groups of six, followed either French or English courses to serve as Control Groups; their level of proficiency corresponded with one of the main Groups, A or B. They were all beginners in French.

\subsection{Teaching Strategies}

Based on communicative views in teaching/learning FLE/EFL and Germain and Netten studies $(2011,2012)$, two current and common textbooks in Iran were selected: American English file (2008) and Le nouveau taxi (2009).

\subsubsection{French Course}

Our approach was adapted in a way to suit Iranian learners' needs. In this course, based on le Nouveau Taxi, conjugations of the verbs along with lists of vocabularies were provided, always in context. Persian was used to facilitate learning where it proved to be useful, such as in teaching possessive adjectives or conjugation. English, the first foreign language of our learners, which serves unconsciously as a model in learning a second foreign language, could be misleading in similar cases.

Producing dialogues was another technique to let learners use newly learnt items. For instance, when lists of professions, nationalities and countries were given, learners would create a new character for themselves like in a game and start comprehensive and sometimes funny conversations, and it was through this practice that they learnt their lessons.

We have profited from the cognates, that is similarities that exist between English and French in teaching items such as certain nouns (e.g.: university/ université, number/ nombre, etc.) or certain structures (e.g.: Quel est votre métier?/ what is your job?). In this regard, the French instructor should be fully aware of false-friends (faux amis), group of similar words in English and French whose meanings are totally different; here are some examples:

- Verb: [En.] support (=backing), [Fr.] supporter (= tolerate, stand), 
- Noun: [En.] raid (= attack), [Fr.] raide (= stiff, steep)

- Adjective: [En.] sensible (=reasonable), [Fr.] sensible (=sensitive),

- Adverb: [En.] actually (= in fact), [Fr.] actuellement (= currently)

Whiteboard markers were used in three colors to show feminine or masculine items of vocabulary and full sentences. This tactic has proved helpful in remembering gender, an essential part of the French language. In this respect, female students were seen to be more attentive.

\subsubsection{English Course}

In this course, based on the textbook American English File, grammar and vocabulary items were taught mainly through free discussions and question/answer activities, all centered on an authentic recent context. Learners were asked to write a paragraph or a three-paragraph article corresponding to their level every three sessions, three times in total. Listening activities were done based on the textbook in the class, but reading activities were assigned for home. The following session, exercises would be done following a friendly chat or debate on a subject chosen from that lesson. Whiteboard markers were used in three colors different from those used in the French classes to facilitate the way students needed to visually distinguish the two languages.

\subsubsection{Instruments and Measures}

We used three tests to determine learning level of our participants: First, we conducted a general English Cambridge placement test accompanied by an interview, twice before and after the classes, to see how their general knowledge in four skills (Speaking, Writing, Reading \& Listening) has changed through the course. Second and third, a final English test and a final French test were taken to control learning through the course. The last two tests, developed directly from the manuals standard evaluations, were adapted to examine the selected parts.

\section{Results}

The results, out of 80 , are presented in the following tables. Participants 1 to 6 were ordered randomly and the raw data of each person is presented to give a better clue to interested educators. Results are to be compared through the mean point.

- Group A: En. Beginners

- Group B: En. Intermediate
* Group CA: Control Group of A

* Group CB: Control Group of B

Table 1. Group A - General English Test

\begin{tabular}{llllllll}
\hline & A1 & A2 & A3 & A4 & A5 & A6 & Mean \\
\hline Before & 27 & 30 & 33 & 31 & 34 & 29 & 30.66 \\
After & 30 & 32 & 36 & 34 & 37 & 32 & 33.5 \\
\hline
\end{tabular}

Table 2. Group B - General English Test

\begin{tabular}{|c|c|c|c|c|c|c|c|}
\hline & B1 & B2 & B3 & B4 & B5 & B6 & Mean \\
\hline Before & 54 & 56 & 56 & 53 & 51 & 55 & 54.16 \\
\hline After & 65 & 68 & 63 & 62 & 69 & 60 & 64.5 \\
\hline
\end{tabular}

Table 3. Group A - Final English Test

\begin{tabular}{lllllllll}
\hline & 1 & 2 & 3 & 4 & 5 & 6 & Mean \\
\hline A & 59 & 60 & 66 & 62 & 68 & 58 & 62.16 \\
CA & 65 & 75 & 70 & 74 & 68 & 69 & 70.16 \\
\hline
\end{tabular}

Table 4. Group B- Final English Test

\begin{tabular}{llllllll}
\hline & 1 & 2 & 3 & 4 & 5 & 6 & Mean \\
\hline B & 65 & 70 & 63 & 60 & 64 & 63 & 64.16 \\
CB & 66 & 75 & 70 & 68 & 65 & 73 & 69.5 \\
\hline
\end{tabular}


Table 5. Group A - Final French Test

\begin{tabular}{llllllll}
\hline & 1 & 2 & 3 & 4 & 5 & 6 & Mean \\
\hline A & 70 & 66 & 72 & 63 & 73 & 60 & 67.33 \\
CA & 56 & 52 & 50 & 43 & 60 & 51 & 52.33 \\
\hline
\end{tabular}

Table 6. Group B - Final French Test

\begin{tabular}{llllllll}
\hline & 1 & 2 & 3 & 4 & 5 & 6 & Mean \\
\hline B & 72 & 75 & 70 & 68 & 65 & 66 & 69.33 \\
CB & 60 & 61 & 63 & 58 & 56 & 59 & 59.5 \\
\hline
\end{tabular}

Table 7. All Groups- Final French Test

\begin{tabular}{lllllll}
\hline & A & CA & B & CB & A+B & CA+CB \\
\hline Mean & 67.33 & 52.83 & 69.33 & 59.5 & 68.33 & 56.16 \\
\hline
\end{tabular}

The results, pinpointed on the average grades of the final exams and the placement tests (given both before and after the course), with a difference of 8 , corresponding to one tenth of whole being considered as meaningful, could be read as follows: unlike Group B, Group A did not exhibit a meaningful progress in the placement test. Although Group A performed meaningfully weaker in the English language compared to the Control Group, the difference is not however significant in beginner levels and teachers do not consider the average of 62 out of 80 very different from 70 out of 80 (personal communication to at least 5 professional teachers).

Group A has obtained better scores in French compared to Control Group A. The difference of 15 points shows that they have successfully surpassed the Control Group. Group B did not perform significantly different from the Control Group in English but significantly better than the Control Group in French. Group B achieved better results than Group A in French, but the difference was not meaningful. On the whole, Groups A and B obtained higher averages than the Control Groups.

\section{Discussion}

The necessity in the modern world of expertise in more than two foreign languages, which has turned out to be almost conventional in European communities, seems unexploited for language learners in Iran. Two of the most required foreign languages in Iran, English and French, are unfortunately of no social benefit nor are close to Persian - the mother tongue. This has made us try to encourage the development of linguistic knowledge through the methods of simultaneous teaching of two foreign languages. Having reflected deeply on simultaneous teaching, we developed 20-session classes of teaching English and French for two groups. This project, to our inquiries, is the first of this nature.

Based on the average grades of the final exams and the placement tests, the results confirm our main hypothesis that simultaneous language learning, if scientifically programmed, can be successful. Placement tests observations can be partly explained by the fact that in lower levels particularly beginners, after a period of ten sessions, we usually do not perceive noticeable improvements. But in intermediate levels, where students are more aware of their learning process, they can better grasp the information presented in the class. Therefore, we may not take this solely as a result of simultaneous learning environment.

Surprisingly better achievements of Group A in French compared to Control Group A, may be described through several reasons the most evident of which could be the enthusiasm and motivation they had in learning two languages simultaneously especially because they were considered equal to Group B who was of higher level in English and this gave them the courage to try more and learn better. This could also be that French was new to them and this freshness could double the effort and joy at the same time. The same reasons stand applicable for Group B since both shared the same conditions in French. In English, as discussed earlier, at intermediate levels, almost parallel progress is normally seen which is the case for our two groups. Since proficiency in the first foreign language could be considered as an influential asset in learning a second foreign language we expected 
that Group B performs better than Group A in French. The results however do not show a significant difference. Still we believe that Group B could spend less time studying and learning and so, the learning process was easier with Group B.

We could conclude that simultaneous learning not only does not act as a deterrent in learning languages but also can be a motivating factor which is the most important dynamic in a language class. Even so, we do not claim that our results could be applicable to all cases but firmly admit that this project can justly serve as a preliminary to such educational programs and serves as a base for larger studies of the same nature, including at least 100 participants, taking into consideration factors such as learners' attitude, disposition, interaction, personality, personal life, mental occupations, gender, both teachers and students, mixed or unisex classes, and intensity of classes, intensive courses, numbers of sessions per week and alteration of each language.

\section{References}

Abutalebi, J. (2008). Neural aspects of second language representation and language control. Acta Psychologica, 128, 466-478. http://dx.doi.org/10.1016/j.actpsy.2008.03.014

Bialystok, E. (2008). Bilingualism: The good, the bad, and the indifferent. Bilingualism: Language and Cognition, 12(1), 3-11. http://dx.doi.org/10.1017/S1366728908003477

Bregy, A. L., Brohy, C., \& Fuchs, G. (2000). Expérience d'apprentissage bilingue précoce : Résultats des élèves de Monthey et de Sion à la fin de la 2e année primaire : Année 1998/1999. Neuchâtel: Institut romand de recherches et de documentation pédagogique.

Capelle, G., \& Menand, R. (2009). Le nouveau taxi. Paris: Hachette.

Fisher, S. E., \& Scharff, C. (2009). FOXP2 as a molecular window into speech and language. Trends in Genetics, 25, 166-177. http://dx.doi.org/10.1016/j.tig.2009.03.002

Germain, C., \& Netten, J. (2011). Impact de la conception de l'acquisition d'une langue seconde ou étrangère sur la conception de la langue et de son enseignement. Synergies Chine, 6, 25-36.

Germain, C., \& Netten, J. (2012). A new paradigm for the learning of a second or foreign language: The neurolinguistic approach. Neuroeducation, 1(1), 85-114.

Gollan, T. H., Fennema-Notestine, C., Montoya, R. I., \& Jernigan, T. L. (2007). The Bilingual Effect on Boston Naming Test Performance. Journal of the International Neuropsychological Society, 13, 197-208.

Gollan, T. H., Montoya, R. I., Cera, C., \& Sandoval, T. C. (2008). More use almost always means a smaller frequency effect: Aging, bilingualism, and the weaker links hypothesis. Journal of Memory and Language, 58, 787-814. http://dx.doi.org/10.1016/j.jml.2007.07.001

Kaushanskaya, M., \& Marian, V. (2007). Bilingual language processing and interference in bilinguals: Evidence from eye tracking and picture naming. Language Learning, 57, 119-163. http://dx.doi.org/10.1111/j.1467-9922.2007.00401.x

Kellerman, E. (1991). Compensatory strategies in second language research: A critique, a revision, and some (non-) implications for the classroom. In R. Phillipson, E. Kellerman, L. Selinker, M. Sharwood Smith, \& M. Swain (Ed.), Foreign/Second Language Pedagogy Research (pp. 142-161). Clevedon: Multilingual Matters.

Kim, K. H. S., Relkin, N. R., Lee K. M., \& Hirsch J. (1997). Distinct cortical areas associated with native and second languages. Nature, 388(6638), 171-174. http://dx.doi.org/10.1038/40623

Kinsella, C. (2009). An investigation into the proficiency of successful late learners of French. Unpublished doctoral dissertationTrinity College, Dublin, Irland.

Kroll, J. F., Bobb, S. C., \& Wodniecka, Z. (2006). Language selectivity is the exception, not the rule: Arguments against a fixed locus of language selection in bilingual speech. Bilingualism: Language and Cognition, 9, 119-135. http://dx.doi.org/10.1017/S1366728906002483

Mehler, J., Pallier, C., \& Christophe, A. (1996). Psychologie cognitive et acquisition des langues. Mini-Synthese: Neurosciences, $n^{\circ}$ spécial, 12(96), 94-99.

Miyake, A., Friedman, N. P., Emerson, M. J., Witzki, A. H., \& Howerter, A. (2000). The unity and diversity of executive functions and their contributions to complex "frontal lobe" tasks: A latent variable analysis. Cognitive Psychology, 41, 49-100. http://dx.doi.org/10.1006/cogp.1999.0734 
Möhle, D. (1989). Multilingual interaction in foreign language production. In H. W. Dechert, \& M. Raupach (Eds.), Interlingual Processes (pp. 179-94). Tübingen: Gunter Narr.

Muñoz, C. (2006). Influence translinguistique et changement de code dans la production orale d'une L4, Acquisition et interaction en langue étrangère [En ligne], 24 | 2006, mis en ligne le 30 juin 2009. Retrieved from http://aile.revues.org/1664

Muñoz, C., \& Singleton, D. (2011). A critical review of age-related research on L2 ultimate attainment. Language Teaching, 44(1), 1-35. http://dx.doi.org/10.1017/S0261444810000327

Navés, T., Miralpeix, I., \& Celaya, M. L. (2005). Who transfers more and what ? CLI in relation to school grade and language dominance in EFL. International Journal of Multilingualism, 2, 113-134. http://dx.doi.org/10.1080/14790710508668380

Odlin, T. (2005). Crosslinguistic Influence and Conceptual Transfer: What are the concepts? Annual Review of Applied Linguistics, 25, 3-25. http://dx.doi.org/10.1017/S0267190505000012

Oxenden, C., Latham-Koenig, C., \& Seligson, P. (2008). American English File. Oxford: Oxford University Press.

Oxford, R. (1990). Language learning strategies: What every teacher should know. New York: Newbury House.

Pavlenko, A., \& Lantolf, J. P. (2000). Second language learning as participation and the (re)construction of selves. In J. P. Lantolf (Ed.), Sociocultural Theory and Second Language Learning (pp. 155-178). Oxford: Oxford University Press.

Perani, D., Abutalebi, J., Paulesu, E., Brambati, S., Scifo, P., Cappa, S. F., \& Fazio, F. (2003). The role of age of acquisition and language usage in early, high-proficient bilinguals: An fMRI study during verbal fluency. Human Brain Mapping, 19, 170-182. http://dx.doi.org/10.1002/hbm.10110

Portocarrero, J. S., Burright, R. G., \& Donovick, P. J. (2007). Vocabulary and verbal fluency of bilingual and monolingual college students. Archives of Clinical Neuropsychology, 22, 415-422. http://dx.doi.org/10.1016/j.acn.2007.01.015

Poulisse, N. (1990). The Use of Compensatory Strategies by Dutch Learners of English. Dordrecht: Foris.

Poulisse, N., \& Bongarets, T. (1994). First language use in second language production. Applied Linguistics, 15, 36-57. http://dx.doi.org/10.1093/applin/15.1.36

Ringbom, H. (1987). The Role of the First Language in Foreign Language Learning. Clevedon: Multilingual Matters.

Trévisiol, P. (2006). Influence translinguistique et alternance codique en français L3, Acquisition et interaction en langue étrangère. L'acquisition d'une langue, 24, 14-43. Retrieved from http://aile.revues.org/1625

Wartenburger, I., Heekeren, H. R., Abutalebi, J., Cappa, S. F., Villringer, A., \& Perani, D. (2003). Early setting of grammatical processing in the bilingual brain. Neuron, 37, 159-170. http://dx.doi.org/10.1016/S0896-6273(02)01150-9

Weber-Fox, C. M., \& Neville, H. J. (1996). Maturational constraints on functional specializations for language processing: ERP and behavioral evidence in bilingual speakers. Journal of Cognitive Neuroscience, 8(3), 231-256. http://dx.doi.org/10.1162/jocn.1996.8.3.231

Wei, L. (2000). Dimensions of Bilingualism. In Li Wei (Ed.), The Bilingualism Reader. London: Routledge. http://dx.doi.org/10.4324/9780203461341

\section{Copyrights}

Copyright for this article is retained by the author(s), with first publication rights granted to the journal.

This is an open-access article distributed under the terms and conditions of the Creative Commons Attribution license (http://creativecommons.org/licenses/by/3.0/). 